\title{
VEGF pathway-targeting drugs induce evasive adaptation by activation of neuropilin-1/cMet in colon cancer cells
}

\author{
CHISATO TOMIDA $^{1}$, NAOKO YAMAGISHI ${ }^{2}$, HIKARU NAGANO ${ }^{3}$, TAKAYUKI UCHIDA $^{1}$, AYAKO OHNO $^{1}$, \\ KATSUYA HIRASAKA ${ }^{4}$, TAKESHI NIKAWA ${ }^{1}$ and SHIGETADA TESHIMA-KONDO ${ }^{3}$ \\ ${ }^{1}$ Department of Physiological Nutrition, Institute of Medical Nutrition, University of Tokushima Graduate School, \\ Kuramoto, Tokushima 770-8503; ${ }^{2}$ Department of Anatomy and Cell Biology, School of Medicine, \\ Wakayama Medical University, Kimiidera, Wakayama 641-8509; ${ }^{3}$ Department of Clinical Nutrition, \\ Osaka Prefecture University Graduate School, Habikino, Osaka 583-8555; ${ }^{4}$ Graduate School of Fisheries Science and \\ Environmental Studies, Nagasaki University, Nagasaki, Nagasaki 852-8521, Japan
}

Received April 13, 2017; Accepted February 12, 2018

DOI: 10.3892/ijo.2018.4291

\begin{abstract}
Anti-angiogenic therapies targeting vascular endothelial growth factor (VEGF) and its receptor (VEGF-R) are important treatments for a number of human malignancies, including colorectal cancers. However, there is increasing evidence that VEGF/VEGF-R inhibitors promote the adaptive and evasive resistance of tumor cells to the therapies. The mechanism by which the cancer cells become resistant remains unclear. One potential mechanism is that VEGF/VEGF-R blockers directly act on tumor cells independently of antiangiogenic effects. In this study, the direct effects of an anti-VEGF antibody (bevacizumab) and a VEGF-R tyrosine kinase inhibitor (sunitinib) on the evasive adaptation of colon cancer cells were compared. HCT116 and RKO human colon cancer cell lines were chronically exposed (3 months) to bevacizumab or sunitinib in vitro to establish bevacizumab- and sunitinib-adapted cells, respectively. Transwell migration and invasion assays, western blotting, reverse transcription-quantitative polymerase chain reaction, co-immunoprecipitation analysis, cell survival assays and ELISAs were conducted to analyze the adapted cells. Compared with the control vehicle-treated cells, the two cell models exhibited increased migration and invasion activities to different degrees and through different mechanisms. The bevacizumab-adapted cells, but not in the sunitinib-adapted cells, exhibited redundantly increased expression levels of VEGF/VEGF-R family members, including VEGF-A, placental growth factor, VEGF-C, VEGF-R1 and VEGF-R3. In addition, the phos-
\end{abstract}

Correspondence to: Dr Shigetada Teshima-Kondo, Department of Clinical Nutrition, Osaka Prefecture University Graduate School, 3-7-30 Habikino, Habikino, Osaka 583-8555, Japan

E-mail: kondoshi@rehab.osakafu-u.ac.jp

Key words: bevacizumab, sunitinib, evasive adaptation, neuropilin-1, cMet phorylation levels of VEGF-R1 and VEGF-R3 were increased in the bevacizumab-adapted cells compared with the control cells. Thus, the inhibition of VEGF-R1 and VEGF-R3 decreased the evasive activities of the cells, suggesting that they remained dependent on redundant VEGF/VEGF-R signaling. By contrast, the sunitinib-adapted cells exhibited increased neuropilin-1 (NRP1) expression levels compared with the control cells. In the sunitinib-adapted cells, NRP1 interacted with phosphorylated cMet, and the cMet activation was dependent on NRP1. Thus, NRP1 or cMet blockade suppressed the evasive activation of the sunitinib-adapted cells. These results suggest that the sunitinib-adapted cells switched from a VEGF-R-dependent pathway to an alternative NRP1/cMet-dependent one. The findings of the present study indicate that VEGF/VEGF-R inhibitors directly act on colon cancer cells and activate their evasive adaptation via different mechanisms.

\section{Introduction}

Vascular endothelial growth factor (VEGF) and VEGFreceptor (VEGF-R) family members are the central regulators of tumor angiogenesis (1). Therefore, several angiogenesis inhibitors targeting the VEGF/VEGF-R pathway have been developed and have become an important option for the management of a number of human malignancies, including colorectal cancer (1-4). However, there is increasing evidence that the clinical results of VEGF/VEGF-R-targeted therapies are very modest, resulting in a moderate improvement in overall survival (5-8). Pre-clinical studies have shown that VEGF/VEGF-R-targeting agents accelerate invasion and metastasis $(9,10)$. Additionally, the clinical outcome is associated with the development of resistance to the VEGF/VEGF-R-targeting agents and the increased risk of invasion and metastasis (11-14). Therefore, acquired and evasive resistance to VEGF/VEGF-R inhibitors is a growing concern in the clinic.

Several mechanisms by which tumor cells acquire resistance to VEGF/VEGF-R pathway targeting therapies 
and escape from aggravated microenvironments have been elucidated (1-4,11). VEGF/VEGF-R blockers primarily target vascular endothelial cells and inhibit tumor angiogenesis, leading to hypoxia within the tumor. Therefore, hypoxic stress is considered to be a central mechanism for the aggressive malignant progression of tumor cells (15-17). Several preclinical studies have shown that VEGF pathway inhibitors facilitate tumor cell invasion and metastasis, which require hypoxic conditions and hypoxia-inducible factors (9-11).

Tumor cells are important targets of VEGF/VEGF-R inhibitors, as several types of cancer cells express functional VEGF-Rs and utilize VEGF as an autocrine survival factor (18-22). Therefore, it is possible that VEGF/VEGF-R blockers could directly act on tumor cells and elicit an adaptive and evasive response, resulting in more aggressive phenotypes. Notably, several studies, including one by the present research group, have shown that the chronic treatment of colon cancer cells with anti-VEGF-A antibody alters their phenotype, for example, by increasing cell motility, apoptosis resistance under hypoxic conditions and spheroid formation (19-22).

VEGF/VEGF-R-targeting agents are classified into the following two groups: Those that target VEGF ligands [VEGF-A, VEGF-B and placental growth factor (PlGF)], such as bevacizumab and aflibercept, and those that target VEGF-Rs (VEGF-R1, -R2 and -R3), including sunitinib, sorafenib, regorafenib, pazopanib, axitinib, vandetanib, dovitinib, nintedanib, lenvatinib, foretinib and cabozantinib (5-7). The aim of the present study was to elucidate whether bevacizumab (a VEGF-A inhibitor) and sunitinib (a blocker of all VEGFRs) directly affect the evasive adaptation of tumor cells. The different mechanisms of evasive activation of the two drugs were also investigated. For this aim, VEGF/VEGF-R inhibitor-adapted cells were developed via the prolonged (3 months) exposure of human colon cancer cell lines to bevacizumab (bevacizumab-adapted cells) or sunitinib (sunitinib-adapted cells). This experiment was based on the observation of tumor invasiveness occurring within a few months of the initiation of treatment with VEGF/VEGF-R-targeting agents in several preclinical models. Notably, preclinical studies have demonstrated that extensive treatment (1-3 months) with sunitinib accelerates local invasion and distant metastasis and leads to a shortening of overall survival $(9,10)$.

\section{Materials and methods}

Reagents. Sunitinib (a VEGF-R tyrosine kinase inhibitor), foretinib [a tyrosine-protein kinase Met (cMet) and VEGF-R tyrosine kinase inhibitor], capmatinib (a selective inhibitor of cMet), GW788388 [a selective inhibitor of transforming growth factor (TGF) $\beta$-RI and -RII], SSR128129E [an allosteric fibroblast growth factor receptor (FGF-R) 1-3 inhibitor], CP-673451 [a selective inhibitor of platelet-derived growth factor receptor (PDGF-R)- $\alpha / \beta$ ] and V1/A7R [a neuropilin-1 (NRP1)-binding heptapeptide, ATWLPPR, that specifically inhibits NRP1) were obtained from Selleck Chemicals (Cosmo Bio Co., Ltd., Tokyo, Japan). Neutralizing antibodies against human hepatocyte growth factor (HGF; MAB294), human NRP1 (AF3870), control non-immune sheep IgG (5-001-A) and control nonimmune mouse IgG (MAB002) were from R\&D Systems, Inc. (Minneapolis, MN, USA). Specific antagonistic inhibitors for VEGF-R1 and VEGF-R3 were purchased from Genscript Japan, Inc. (Tokyo, Japan).

Establishment of cell models adapted to bevacizumab and sunitinib. Human colon cancer cell lines (HCT116 and RKO) were obtained from American Type Culture Collection (Manassas, VA, USA) and maintained in RPMI-1640 medium (Nacalai Tesque, Inc., Tokyo, Japan) with $10 \%$ fetal bovine serum (FBS; SAFS Biosciences; Merck KGaA, Darmstadt, Germany), $100 \mathrm{U} / \mathrm{ml}$ penicillin and $0.1 \mathrm{mg} / \mathrm{ml}$ streptomycin (both from Nacalai Tesque, Inc.) at $37^{\circ} \mathrm{C}$ under $5 \% \mathrm{CO}_{2}$ and 95\% air. To establish the bevacizumab-adapted cells (HCT/bev and $\mathrm{RKO} / \mathrm{bev}$, respectively), cells were chronically exposed to bevacizumab (Chugai Pharmaceuticals Co., Ltd., Tokyo, Japan) for 3 months at a clinically relevant dose $(100 \mu \mathrm{g} / \mathrm{ml})$, based on the US Food and Drug Administration-approved bevacizumab dose $(5 \mathrm{mg} / \mathrm{kg})$ corresponding to a concentration of $100 \mu \mathrm{g} / \mathrm{ml}$ in cell culture experiments (20). To develop the sunitinib-adapted cells (HCT/suni and RKO/suni, respectively) or foretinib-adapted cells (HCT/fore and RKO/fore, respectively), cells were chronically treated with a pharmacologically relevant concentration of sunitinib $(0.1 \mu \mathrm{M})$ or foretinib (5 nM) for 3 months $(23,24)$. The vehicle-treated control cells (HCT/ctl and RKO/ctl, respectively) were obtained by chronic treatment with DMSO (0.005\%) for 3 months.

The bevacizumab-adapted cells were pretreated with DMSO (0.005\%), VEGF-R1 inhibitor $(50 \mu \mathrm{M})$ or VEGF-R3 inhibitor $(75 \mu \mathrm{M})$ for $1 \mathrm{~h}$ at $37^{\circ} \mathrm{C}$, and then their migration and invasion abilities were determined. The control and sunitinib-adapted cells were pretreated with vehicle (DMSO, 0.005\%), capmatinib $(2 \mathrm{nM}), \mathrm{GW} 788388(0.35 \mu \mathrm{M}), \operatorname{SSR} 128129 \mathrm{E}(0.2 \mu \mathrm{M})$, CP-673451 (0.05 $\mu \mathrm{M})$, NRP1 antagonist V1/A7R (3 $\mu \mathrm{M})$, antiNRP1 neutralizing antibody $(5 \mu \mathrm{g} / \mathrm{ml})$, anti-HGF neutralizing antibody $(1 \mu \mathrm{g} / \mathrm{ml})$, a control non-immune sheep $\operatorname{IgG}(5 \mu \mathrm{g} / \mathrm{ml}$; as a control for anti-NRP1 neutralizing antibody) or a control non-immune mouse $\mathrm{IgG}(1 \mu \mathrm{g} / \mathrm{ml}$; as a control for anti-HGF neutralizing antibody) for $1 \mathrm{~h}$ at $37^{\circ} \mathrm{C}$, and then their migration and invasion activities were evaluated. Parental HCT116 and RKO cells were pretreated with vehicle (DMSO, 0.005\%), sunitinib $(0.1 \mu \mathrm{M})$ or foretinib $(10 \mathrm{nM})$ for $48 \mathrm{~h}$ at $37^{\circ} \mathrm{C}$, then their migration and invasion activities were examined.

Cell migration and invasion assay. Equal numbers of cells (50,000 cells) were suspended in $0.25 \mathrm{ml}$ RPMI-1640 containing $1 \%$ FBS with various treatment agents, as described in the section entitled 'establishment of cell models adapted to bevacizumab and sunitinib', and then placed in the top compartment of an uncoated $8-\mu \mathrm{m}$ pore membrane chamber (BD Biosciences, Franklin Lakes, NJ, USA); $0.75 \mathrm{ml}$ RPMI-1640 containing 4\% FBS for the migration assay or $10 \%$ FBS for the invasion assay was added to the bottom compartment. Following 24-48 h incubation under standard conditions $\left(37^{\circ} \mathrm{C} / 5 \% \mathrm{CO}_{2}\right)$, non-migrating cells were scraped from the top compartment, and cells that had migrated to the bottom compartment were fixed with $100 \%$ methanol at $25^{\circ} \mathrm{C}$ for $30 \mathrm{sec}$, and stained at $25^{\circ} \mathrm{C}$ for $30 \mathrm{sec}$ using Hemacolor Rapid staining of blood smear (Merck KGaA). Membranes were excised and mounted on a standard microscope slide. The numbers of migrated cells were determined from 4-6 random high-power fields visualized at x20 magnification. 
Invasion assays were performed using a protocol similar to that of the migration assay with minor modifications. The inserts used in the invasion assays were coated with Matrigel (BD Biosciences) and prehydrated with $1 \%$ FBS-supplemented medium for $2 \mathrm{~h}$ prior to the addition of the cell suspension. Following 48-h incubation under standard conditions $\left(37^{\circ} \mathrm{C} / 5 \% \mathrm{CO}_{2}\right)$, the numbers of invading cells were quantified as described above.

Reverse transcription-quantitative polymerase chain reaction $(R T-q P C R)$. The extraction of total RNA was carried out using an RNeasy mini kit (Qiagen, Tokyo, Japan), and total RNA $(1 \mu \mathrm{g})$ was used to synthesize cDNA using the PrimeScript RT reagent kit (Takara Bio, Inc., Tokyo, Japan) according to the following steps: $37^{\circ} \mathrm{C}$ for $10 \mathrm{~min}, 85^{\circ} \mathrm{C}$ for $30 \mathrm{sec}$, and cooling down to $4^{\circ} \mathrm{C}$. The levels of transcripts for human NRPI and human $G A P D H$ in the cells were measured by RT-qPCR using the following specific primer sets: NRP1, 5'-CCCTGAGAA TGGGTGGACT-3' (forward) and 5'-CGTGACAAAGCGCAG AAG-3' (reverse); GAPDH, 5'-GCTAGGGACGGCCTGAAG-3' (forward) and 5'-GCCCAATACGACCAAATCC-3' (reverse). qPCR analysis was performed using a SYBR-Green Master Mix (Applied Biosystems; Thermo Fisher Scientific, Inc., Waltham, MA, USA) according to the following steps: $95^{\circ} \mathrm{C}$ for $30 \mathrm{sec}(1 \mathrm{cycle}), 60^{\circ} \mathrm{C}$ for $30 \mathrm{sec}$ and $95^{\circ} \mathrm{C}$ for $5 \mathrm{sec}(40 \mathrm{cycles})$. Amplification and quantification of the PCR products were performed using the Applied Biosystems 7500 System (Applied Biosystems; Thermo Fisher Scientific, Inc.). Standards were run in the same plate and the relative standard curve quantification method was used to calculate the relative mRNA expression (25). RNA quantities were normalized against the GAPDH mRNA levels.

Western blot analysis. Total cell lysates were prepared using a lysis buffer containing $100 \mathrm{mM}$ Tris- $\mathrm{HCl}$ (pH 6.8), $300 \mathrm{mM}$ $\mathrm{NaCl}, 2$ mM EDTA and 4\% (v/v) sodium dodecylsulfate (SDS). Protein concentrations were determined using a bicinchoninic acid protein assay (Pierce; Thermo Fisher Scientific, Inc.). The cell extracts (50 $\mu \mathrm{g}$ protein/lane) were subjected to $10 \%$ SDS-polyacrylamide gel electrophoresis (PAGE) and transferred to a polyvinylidene difluoride membrane (EMD Millipore, Bedford, MA, USA). The membrane was blocked with $4 \%$ skimmed milk for $1 \mathrm{~h}$ at $25^{\circ} \mathrm{C}$, and then incubated for $15 \mathrm{~h}$ at $4^{\circ} \mathrm{C}$ in phosphate-buffered saline (PBS) containing $0.05 \%$ Tween-20 with the primary antibody according to the instructions provided by the manufacturer; a rabbit monoclonal anti-human NRP1 antibody (D62C6) at 1:3,000 dilution, a rabbit monoclonal anti-human cMet antibody (D1C2) at 1:2,000 dilution, a rabbit monoclonal anti-human phospho-cMet (Tyr1234/Tyr1235) antibody (D26) at 1:3,000 dilution, a rabbit monoclonal anti-human p130Cas antibody (E1L9G) at 1:2,000 dilution, a rabbit monoclonal anti-human phospho-p130Cas (Tyr410) antibody (\#4011) at a 1:1,000 dilution, a rabbit monoclonal anti-human Slug antibody (C19G7) at a 1:1,000 dilution, a rabbit monoclonal anti-human N-cadherin antibody (D4R1H) at a 1:2,000 dilution and a mouse monoclonal anti-human $\beta$-actin antibody (8H10D10) at a 1:10,000 dilution. All primary antibodies were acquired from Cell Signaling Technology, Inc. (Danvers, MA, USA). The membrane was probed for $1 \mathrm{~h}$ at $25^{\circ} \mathrm{C}$ with secondary antibodies; anti-rabbit IgG horseradish peroxidase (HRP)-linked antibody at a 1:10,000 dilution (\#7074) and anti-mouse IgG HRP-linked antibody at a 1:10,000 dilution (\#7076) (both from Cell Signaling Technology, Inc.). The membranes were developed using ECL western blot detection reagents (GE Healthcare Life Sciences, Little Chalfont, UK).

Co-immunoprecipitation analysis. For NRP1/cMet co-immunoprecipitation analysis, cells were crosslinked with dithiobis(succinimidyl propionate) (Pierce; Thermo Fisher Scientific, Inc.) prior to cell lysis. Cells were harvested in ice-cold lysis buffer (50 mM HEPES, pH 7.0, $150 \mathrm{mM}$ $\mathrm{NaCl}, 10 \mathrm{mM}$ EDTA, $1.5 \mathrm{mM} \mathrm{MgCl}_{2}, 1 \%$ Nonidet P-40, $1 \%$ Triton X-100, $1 \mathrm{mM}$ phenylmethylsulfonyl fluoride, $1 \mathrm{mM}$ sodium orthovanadate, $0.5 \%$ sodium deoxycholate, $5 \mathrm{mg} / \mathrm{ml}$ aprotinin, $5 \mathrm{mg} / \mathrm{ml}$ leupeptin, $20 \mathrm{mM}$ sodium fluoride and $20 \mathrm{mM}$ sodium pyrophosphate), homogenized through a 23 -gauge needle 10 times, then centrifuged at $10,000 \mathrm{x} \mathrm{g}$ for $20 \mathrm{~min}$ at $4^{\circ} \mathrm{C}$. The clarified lysate $(1 \mathrm{mg})$ was incubated with a rabbit monoclonal anti-human NRP1 antibody (D62C6) overnight at $4^{\circ} \mathrm{C}$ with constant gentle rocking, followed by the addition of Protein $\mathrm{G}$ magnet Dynabeads (Thermo Fisher Scientific, Inc.) for $4 \mathrm{~h}$ at $4^{\circ} \mathrm{C}$. The immunoprecipitates were washed, eluted with SDS-PAGE sample buffer, and subjected to SDS-PAGE using 4-20\% polyacrylamide gradient gels. They were transferred to a polyvinylidene difluoride membrane (EMD Millipore). The membrane was blocked with $4 \%$ skimmed milk for $1 \mathrm{~h}$ at $25^{\circ} \mathrm{C}$, and then incubated for $15 \mathrm{~h}$ at $4^{\circ} \mathrm{C}$ in PBS containing $0.05 \%$ Tween- 20 with the primary antibody; a rabbit monoclonal anti-human cMet antibody (D1C2) at 1:2,000 dilution, a rabbit monoclonal anti-human phosphocMet (Tyr1234/Tyr1235) antibody (D26) at 1:3,000 dilution, and rabbit monoclonal anti-human NRP1 antibody (D62C6) at 1:3,000 dilution. All primary antibodies were acquired from Cell Signaling Technology, Inc. The membrane was probed for $1 \mathrm{~h}$ at $25^{\circ} \mathrm{C}$ with anti-rabbit IgG HRP-linked antibody at a 1:10,000 dilution (\#7074; Cell Signaling Technology, Inc.). The membranes were developed using ECL western blot detection reagents (GE Healthcare Life Sciences).

Cell survival assay. Cell survival was assessed using a CellTiter $96^{\circledR}$ AQueous One Solution Cell Proliferation Assay (Promega Corporation, Madison, WI, USA), according to the manufacturer's protocol. Cells were plated $\left(1 \times 10^{4}\right.$ cells/well) in a 96-well flat-bottom plate for $24 \mathrm{~h}$, then they were treated with sunitinib $(0.1,1$ or $10 \mu \mathrm{M})$ or with bevacizumab $(10$ or $100 \mu \mathrm{g} / \mathrm{ml})$ for 3 days. Following treatment, $100 \mu \mathrm{l}$ RPMI-1640 medium containing the 3-(4,5-dimethylthiazol-2-yl)-5-(3-carboxymethoxyphenyl)-2-(4-sulfophenyl)-2H-tetrazolium reagent (20 $\mu \mathrm{l} /$ well) was added to each well and the cells were incubated for $1 \mathrm{~h}$ at $37^{\circ} \mathrm{C}$. The levels of blue formazan were measured spectrophotometrically at $490 \mathrm{~nm}$ immediately using a microplate reader (Wallac 1420 ARVO MX; PerkinElmer, Inc., Waltham, MA, USA).

ELISA. Secreted VEGF ligands (VEGF-A, PIGF and VEGF-C) in the cell culture supernatants were measured using a VEGF isotype-specific ELISA kit (DVE00, DPG00 and DVEC00; R\&D Systems, Inc.) according to the manufacturer's protocol. Notably, an ELISA that measures VEGF-B was not available 
A
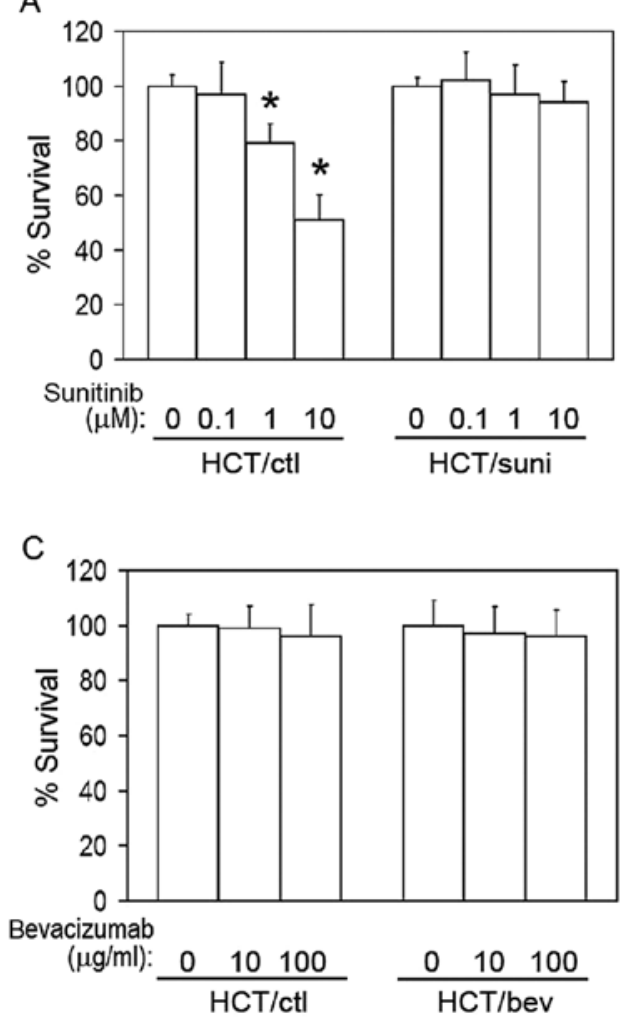

B

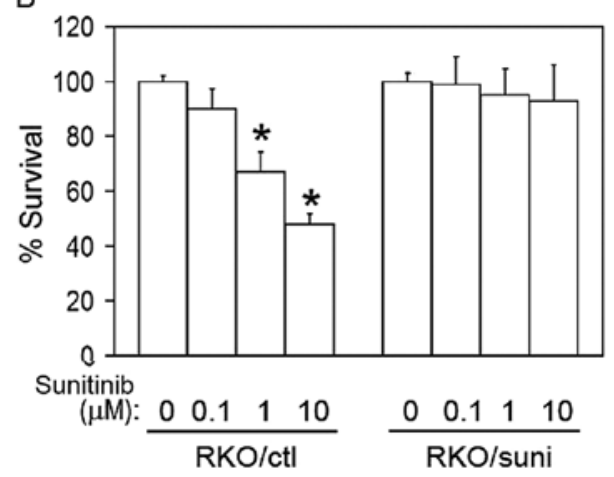

D

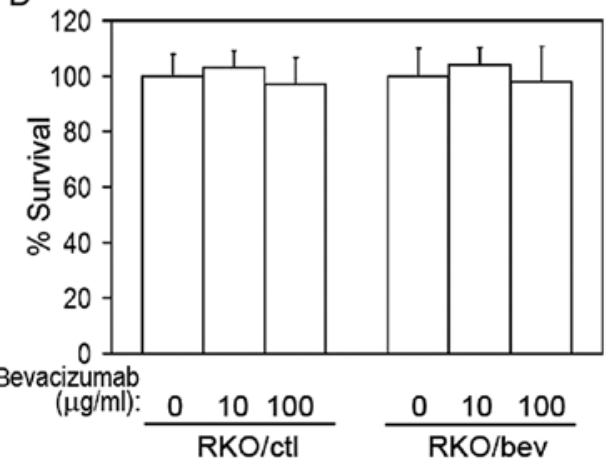

Figure 1. Characterization of the sunitinib- and bevacizumab-adapted cells. Survival of the control and sunitinib-adapted (A) HCT116 and (B) RKO cells in the absence or presence of sunitinib at the indicated concentrations. Survival of the control and bevacizumab-adapted (C) HCT116 and (D) RKO cells in the absence or presence of bevacizumab at the indicated concentrations. Data are presented as the mean \pm standard deviation ( $\mathrm{n}=5$ ). ${ }^{*} \mathrm{P}<0.01$ vs. the respective vehicle (dimethylsulfoxide)-treated cells. HCT/ctl, control HCT116 cells; RKO/ctl, control RKO cells; HCT/suni, sunitinib-adapted HCT116 cells; RKO/suni, sunitinib-adapted RKO cells; HCT/bev, bevacizumab-adapted HCT116 cells; RKO/bev, bevacizumab-adapted RKO cells.

from R\&D Systems, Inc. when the study was conducted. Total and phosphorylated VEGF-Rs (R1 and R3) in cell lysates were measured using the respective human VEGF-R DuoSet IC ELISA kit and the respective human Phospho-VEGF-R DuoSet IC ELISA kit (both from R\&D Systems, Inc.) according to the manufacturer's protocol.

Statistical analysis. Results are expressed as the mean \pm standard deviation. Differences between groups were analyzed via analysis of variance and Scheffe's test using SPSS software (release 6.1; SPSS Japan, Tokyo, Japan). P<0.01 was considered to indicate a statistically significant difference.

\section{Results}

Development and characterization of sunitinib-and bevacizumab-adapted cells. The human colon cancer cell lines HCT116 and RKO were selected because they express several VEGF/VEGF-R family members and utilize autocrine VEGF signals for their survival; this has been demonstrated by several groups, including the present research team (20-22). To investigate the direct effects of sunitinib and bevacizumab, two cell models (sunitinib- and bevacizumab-adapted cells) were established by continuously culturing the cells in the presence of sunitinib or bevacizumab for 3 months; a similar procedure has been used in previous studies $(21,22)$.

To characterize the resistance of the sunitinib-adapted cells (HCT/suni and RKO/suni) to sunitinib, the cells were treated with sunitinib at several concentrations and analyzed using a cell survival assay (Fig. 1A and B). A marked resistance to sunitinib was observed in the sunitinib-adapted cells compared with the respective vehicle-treated control cells (Fig. 1A and B). However, the bevacizumab-adapted cells (HCT/bev and RKO/bev) exhibited similar growth rates to their respective control cells when treated with bevacizumab (Fig. 1C and D).

Cell migration and invasion activities of the bevacizumaband sunitinib-adapted cells. It has been reported that bevacizumab-adapted cells exhibit increased motility and invasive activities (21). Thus, these activities were compared in the bevacizumab- and sunitinib-adapted cells in the present study. A modified Boyden chamber assay demonstrated that the migration activities of the bevacizumab-adapted cells were significantly increased compared with those of the control cells (Fig. 2A-D). The sunitinib-adapted cells showed significant increases in migration activities compared with those of the control and of the bevacizumab-adapted cells (Fig. 2A-D). Cell invasion was also examined using a Matrigel invasion assay. Consistent with the migration activity, the invasion activities of the bevacizumab-adapted cells were significantly increased compared with those of the control cells Fig. 2E-H). The sunitinib-adapted cells exhibited significant increases in invasion activities compared with the control and with the bevacizumabadapted cells (Fig. 2E-H). These findings indicate that the evasive phenotype was more potently activated by the inhibition 
A

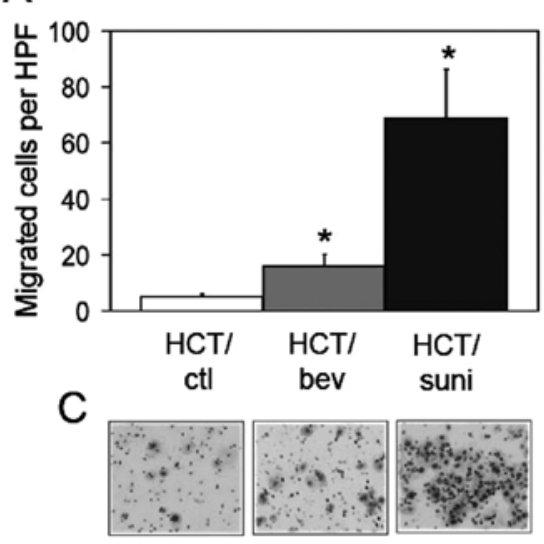

E

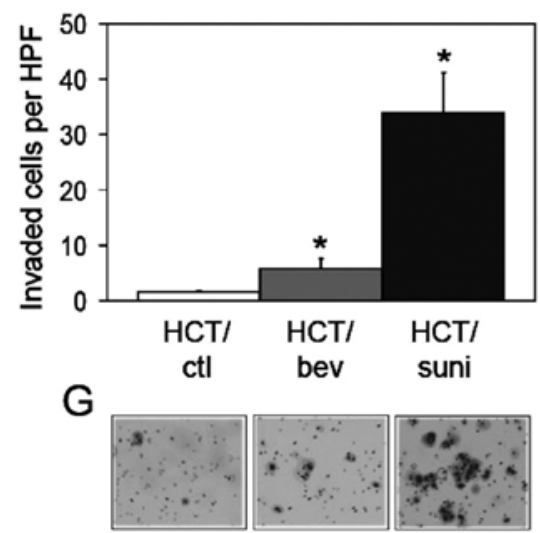

B

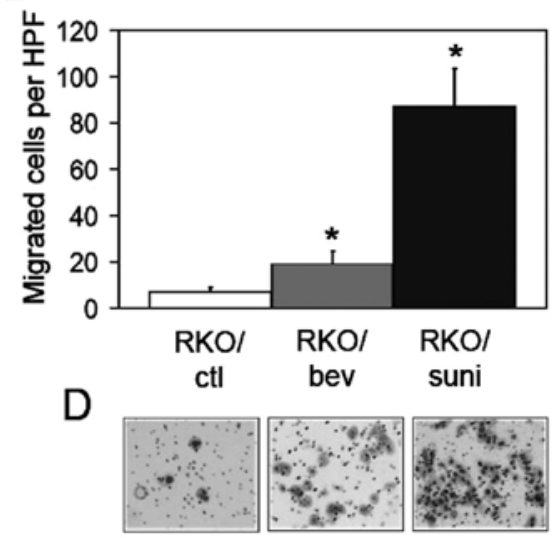

F

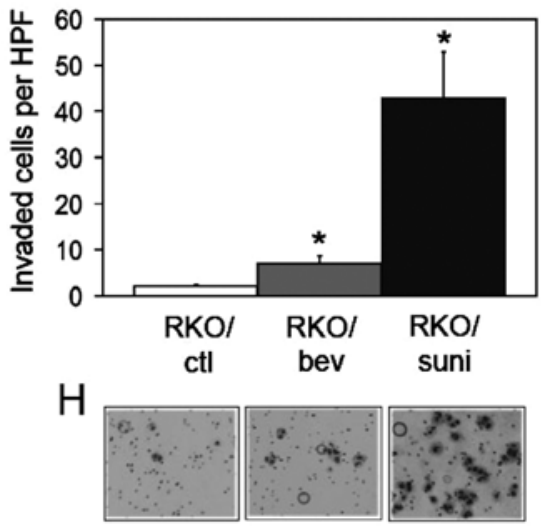

Figure 2. Effect of bevacizumab or sunitinib on migration and invasion activities. Migration of the control, bevacizumab-adapted and sunitinib-adapted (A) HCT116 and (B) RKO cells was determined by an uncoated Transwell migration assay ( $\mathrm{n}=4-6$; mean \pm standard deviation). Representative photographs of the migrated (C) HCT116 and (D) RKO cells. Invasion of the control, bevacizumab-adapted and sunitinib-adapted (E) HCT116 and (F) RKO cells was determined by a Matrigel-coated Transwell invasion assay ( $n=4-6$; mean \pm standard deviation). Representative photographs of the invaded (G) HCT116 and $(\mathrm{H}) \mathrm{RKO}$ cells. ${ }^{*} \mathrm{P}<0.01$ vs. the respective control cells; ${ }^{*} \mathrm{P}<0.01$ vs. the respective bevacizumab-adapted cells. HCT/ctl, control HCT116 cells; RKO/ctl, control RKO cells; HCT/suni, sunitinib-adapted HCT116 cells; RKO/suni, sunitinib-adapted RKO cells; HCT/bev, bevacizumab-adapted HCT116 cells; RKO/bev, bevacizumab-adapted RKO cells; HPF, high power field.

of all VEGF-Rs compared with inhibition of the VEGF-A ligand alone and suggest that the evasive activation was induced by a different mechanism under the VEGF-R-inhibited conditions compared with the VEGF-A-inhibited conditions.

Different mechanisms of evasive adaptation in the bevacizumab-and sunitinib-adapted cells. Whether the mechanism of evasive adaptation differed between the bevacizumab- and sunitinib-adapted cells was investigated. It was hypothesized that the bevacizumab-adapted cells may redundantly depend on VEGF/VEGF-R family members aside from VEGF-A whereas the sunitinib-adapted cells may be independent of these proteins because all VEGF-Rs are inhibited in the cells. To test this hypothesis, the expression profiles of VEGF ligands and their receptors at the protein levels were compared in the two cell models using ELISAs. Consistent with the aforementioned hypothesis, the bevacizumab-adapted cells exhibited a significant increase in the expression levels of VEGF-A, PIGF, VEGF-C, VEGF-R1 and VEGF-R3 compared with the control cells among the VEGF family members tested (Fig. 3A-E). Additionally, the phosphorylated levels of VEGF-R1 and VEGF-R3 were significantly elevated in the bevacizumab-adapted cells compared with the control cells (Fig. 3F and G), suggesting that the bevacizumab-adapted cells utilize VEGF-R1 and VEGF-R3 autocrine systems. By contrast, the sunitinib-adapted cells did not demonstrate any significant difference in the expression of VEGF family members when compared with the control cells (Fig. 3).

To investigate whether the bevacizumab-adapted cells utilized VEGF-R1 and VEGF-R3 systems for their evasive adaptation, specific antagonistic inhibitors for VEGF-R1 (26) or VEGF-R3 (27) were used. Treatment with the VEGF-R1 inhibitor significantly decreased the migration and invasion activities of the $\mathrm{HCT} / \mathrm{bev}$ and $\mathrm{RKO} /$ bev cells compared with the DMSO-treated controls (Fig. 4). When VEGF-R3 was blocked, the evasive activities of the HCT/bev and RKP/bev cells were also significantly inhibited compared with the DMSO-treated controls (Fig. 4). These results support the hypothesis that the bevacizumab-adapted cells were redundantly dependent on VEGF family members.

To clarify the mechanism in the sunitinib-adapted cells, the present study focused on NRP1 as it is a multifunctional co-receptor involved in migration and invasion in several cancer cells (28-30). Thus, the expression levels of NRP1 were evaluated 
Control cells

Bevacizumab-adapted cells

Sunitinib-adapted cells
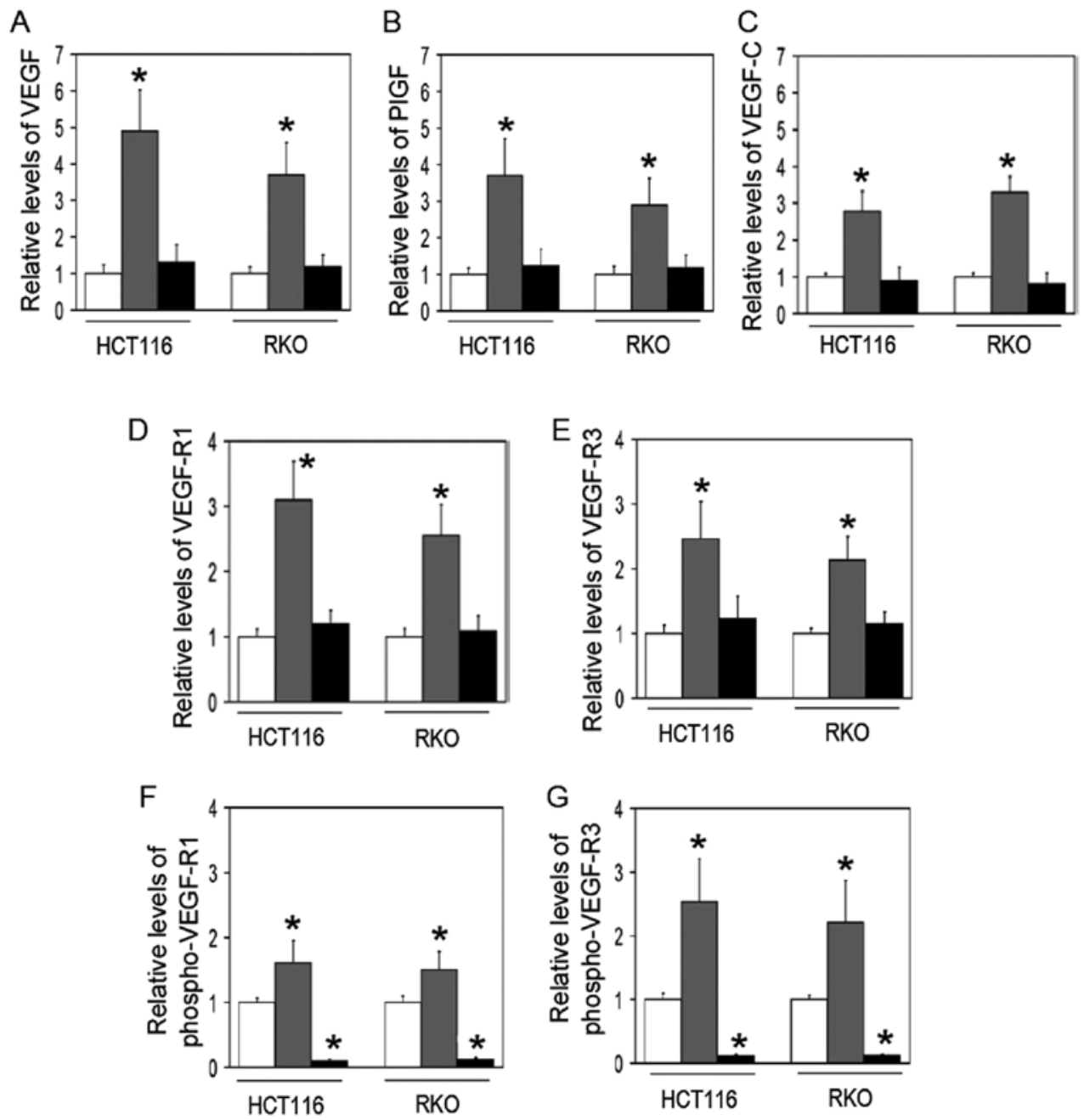

Figure 3. Expression of VEGF family members in the bevacizumab- and the sunitinib-adapted cells. Protein expression levels of (A) VEGF-A, (B) PlGF, (C) VEGF-C, (D) VEGF-R1, (E) VEGF-R3, (F) phosphorylated VEGF-R1 and (G) phosphorylated VEGF-R3 were measured using ELISAs. Values are shown as the levels relative to those of the respective control cells $\left(\mathrm{n}=3\right.$; mean \pm standard deviation). ${ }^{\text {" }}<<0.01$ vs. the respective control cells. VEGF, vascular endothelial growth factor; PIGF, placental growth factor; VEGF-R, VEGF receptor.

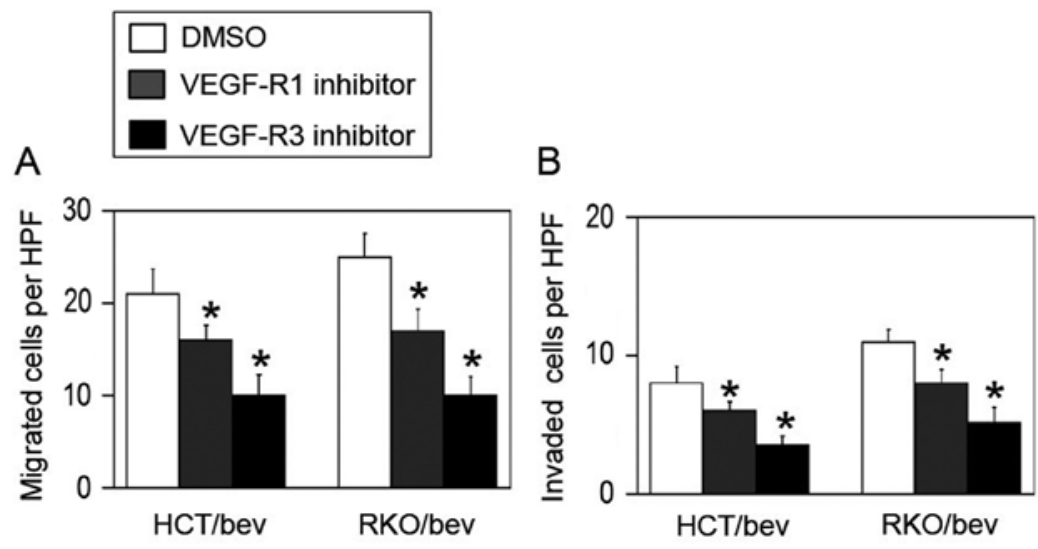

Figure 4. Bevacizumab-adapted cells depend on VEGF-R1 and VEGF-R3. The bevacizumab-adapted cells were pretreated with DMSO, VEGF-R1 inhibitor or VEGF-R3 inhibitor for $1 \mathrm{~h}$, and then their (A) migration and (B) invasion abilities were determined in the presence of the respective agent ( $\mathrm{n}=4-6$; mean \pm standard deviation). "P<0.01 vs. the DMSO-treated cells. VEGF-R, vascular endothelial growth factor receptor; DMSO, dimethylsulfoxide; HCT/bev, bevacizumab-adapted HCT116 cells; RKO/bev, bevacizumab-adapted RKO cells; HPF, high power field. 
A
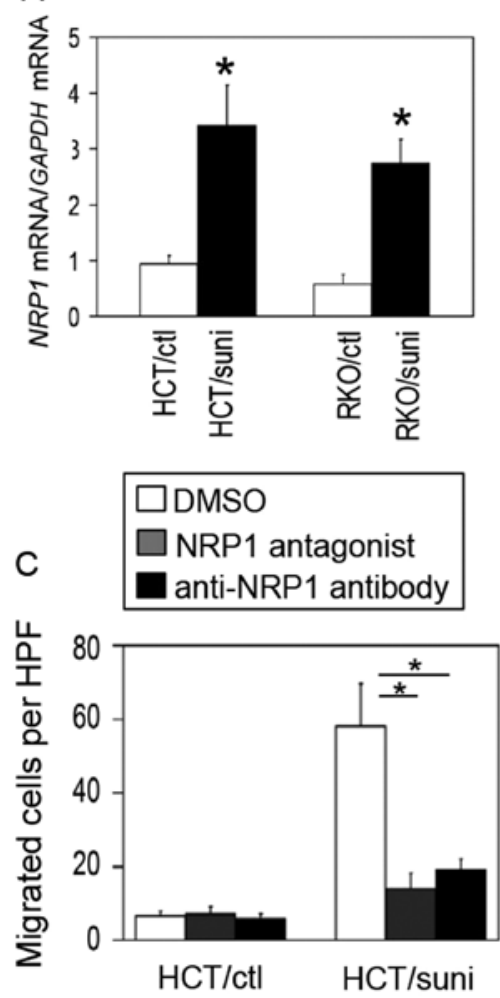

E

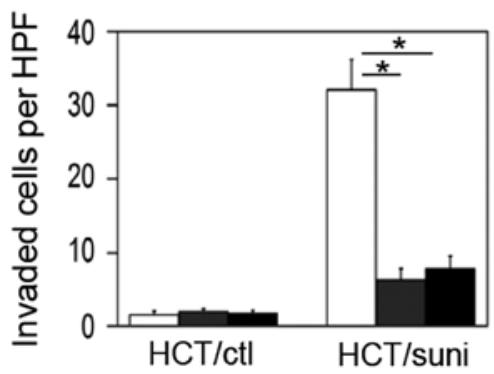

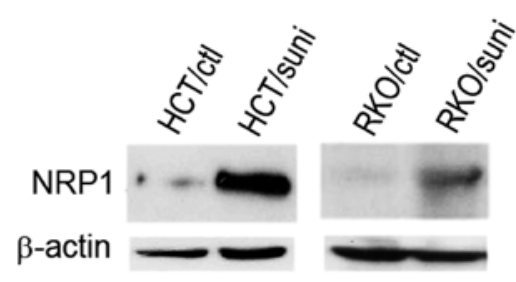

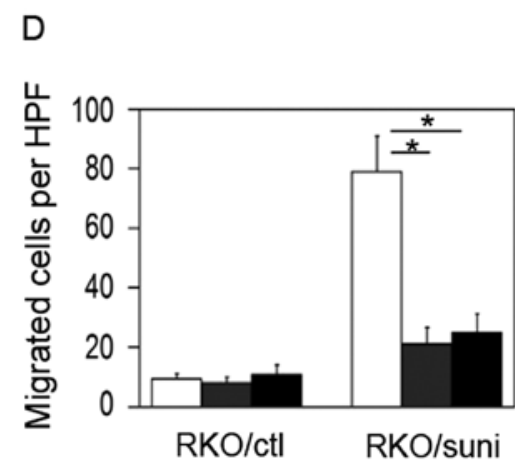

$\mathrm{F}$

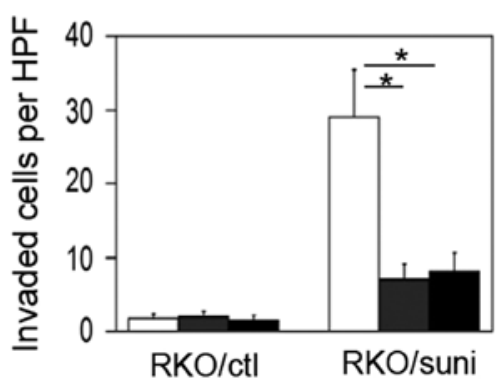

Figure 5. Sunitinib-adapted cells depend on NRP1. (A and B) The expression of NRP1 was increased in the sunitinib-adapted cells. (A) Expression levels of $N R P 1$ mRNA in the control and sunitinib-adapted cells were measured using reverse transcription-quantitative polymerase chain reaction (n=5; mean \pm standard deviation). ${ }^{*} \mathrm{P}<0.01$ vs. the respective control cells. (B) Representative western blot analysis of NRP1 protein expression levels in the control and the sunitinib-adapted cells $(n=3)$. The levels of $\beta$-actin are shown as a loading control. (C-F) Effect of NRP1 blockade on the evasive activation of the sunitinibadapted cells. The control and the sunitinib-adapted cells were pretreated for $24 \mathrm{~h}$ with vehicle (DMSO), NRP1 antagonist or anti-NRP1 neutralizing antibody and their migration and invasion activities were evaluated. Migration activities of (C) HCT116 and (D) RKO cells and invasion activities of (E) HCT116 and (F) RKO cells are shown ( $\mathrm{n}=4-6$; mean \pm standard deviation). ${ }^{*} \mathrm{P}<0.01$ as indicated. NRP1, neuropilin-1; DMSO, dimethylsulfoxide; HCT/ctl, control HCT116 cells; RKO/ctl, control RKO cells; HCT/suni, sunitinib-adapted HCT116 cells; RKO/suni, sunitinib-adapted RKO cells; HPF, high power field.

in the sunitinib-adapted cells. As shown in Fig. 5A and B, NRP1 expression was increased at the mRNA and protein levels in the sunitinib-adapted cells compared with the control cells.

To block NRP1 function, two different types of inhibitors [an NRP1 antagonistic peptide, which binds to the NRP1 extracellular domain (31), and a neutralizing anti-NRP1 antibody] were used. Treatment with the NRP1 blockers significantly decreased the migration and invasion activities of the sunitinib-adapted cells but not the control cells when compared with the respective DMSO-treated controls (Fig. 5C-F). These results indicate that the sunitinib-adapted cells switched from a VEGF-R-dependent phenotype to an NRP1-dependent one.

Identification of the NRPI partner receptor in the sunitinibadapted cells. The NRP1-dependent evasive mechanism in the sunitinib-adapted cells was investigated. NRP1 functions as a co-receptor for several growth factor receptors, including cMet, TGF $\beta-R$, FGF-R and PDGF-R (28-30). To explore the partner receptor of NRP1, receptor kinase inhibitors specific for cMet (capmatinib), TGF $\beta-R$ (GW788388), FGF-R (SSR128129E) and PDGF-R (CP-673451) were used. As shown in Fig. 6A and B, the inhibition of cMet, but not of TGF $\beta-R$, FGF-R and PDGF-R, significantly reduced the migration activity of the sunitinib-adapted cells compared with that of the DMSO-treated control. By contrast, blocking cMet did not affect the control cells.

To further confirm the involvement of cMet in the evasive activation of the sunitinib-adapted cells, the effect of blocking the HGF derived from the cells was examined. As shown in Fig. 6C and D, the blockade of HGF with an anti-HGF 


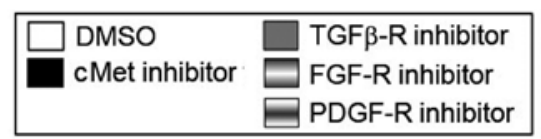

A
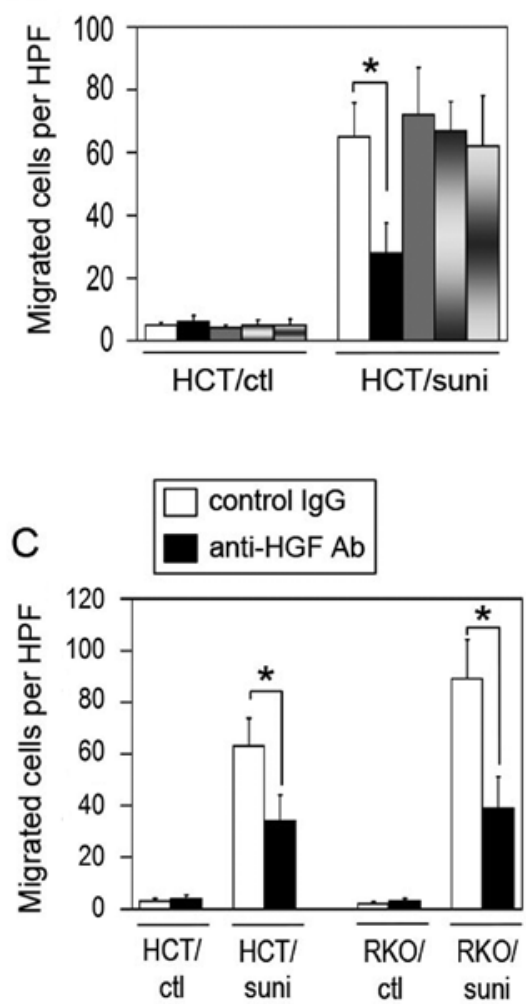

B

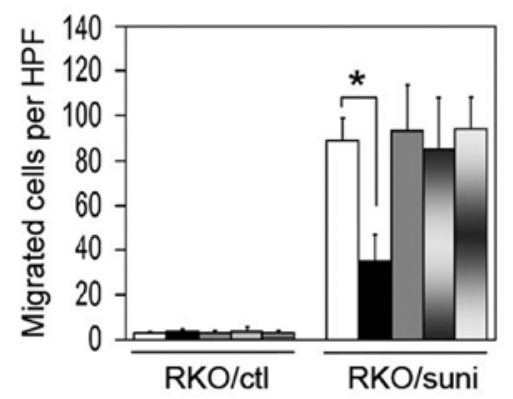

D



Figure 6. cMet participates in the evasive activation of the sunitinib-adapted cells. Effect of the inhibition of cMet, TGF 3 -R, FGF-R or PDGF-R on the migration activity in the sunitinib-adapted (A) HCT116 and (B) RKO cells. The control and sunitinib-adapted cells were pretreated for $24 \mathrm{~h}$ with vehicle (DMSO), cMet inhibitor (capmatinib), TGF $3-R$ inhibitor (GW788388), FGF-R inhibitor (SSR128129E) or PDGF-R inhibitor (CP-673451), and the migration activity of the cells was analyzed ( $\mathrm{n}=4-5$; mean \pm standard deviation). ${ }^{*} \mathrm{P}<0.01$ vs. the respective DMSO-treated control cells. (C and D) Blockade of tumor cell-derived HGF suppresses the migration and invasion activities of the sunitinib-adapted cells. The control and sunitinib-adapted cells were pretreated for $24 \mathrm{~h}$ with a control non-immune IgG or anti-HGF neutralizing antibody, then their (C) migration and (D) invasion activities were evaluated ( $\mathrm{n}=4-5$; mean \pm standard deviation). ${ }^{*} \mathrm{P}<0.01$ vs. the respective control IgG-treated cells. cMet, tyrosine-protein kinase Met; TGF $\beta-\mathrm{R}$, transforming growth factor $\beta$ receptor; FGF-R, fibroblast growth factor receptor; PDGF-R, platelet-derived growth factor receptor; DMSO, dimethylsulfoxide; HGF, hepatocyte growth factor; IgG, immunoglobulin G; $\mathrm{Ab}$, antibody; HCT/ctl, control HCT116 cells; RKO/ctl, control RKO cells; HCT/suni, sunitinib-adapted HCT116 cells; RKO/suni, sunitinib-adapted RKO cells; HPF, high power field.

neutralizing antibody significantly reduced the migration and invasion activities of the sunitinib-adapted cells but not the control cells compared with the respective IgG-treated control cells. These results are similar to those for cMet inhibition (Fig. 6A and B).

NRP1-dependent cMet activation in the sunitinib-adapted cells. The results observed in Figs. 5 and 6 suggest that NRP1 participated in cMet activation in the sunitinib-adapted cells. To test this, the cMet phosphorylation levels were evaluated by immunoblot analysis. As shown in Fig. 7A, the levels of phospho-cMet were increased in the sunitinib-adapted cells compared with the control cells. Whether NRP1 was required for cMet phosphorylation in the sunitinib-adapted cells was then investigated. Blocking NRP1 markedly reduced the levels of phosphorylated cMet (Fig. 7B) but did not affect the expression levels of total cMet in the sunitinib-adapted cells, indicating that cMet activation is dependent on NRP1.

To further investigate whether NRP1 physically interacted with cMet and was associated with its activation in the sunitinib-adapted cells, immunoprecipitation in combination with immunoblot analysis was performed. NRP1 protein was immunoprecipitated, and then the levels of co-precipitated cMet and its phosphorylation were measured by immunoblot analysis. The association of NRP1 with cMet was increased in the sunitinibadapted cells compared with the control cells (Fig. 7C, upper panel). Importantly, the co-precipitation of phosphorylated cMet was observed only in the sunitinib-adapted cells (Fig. 7C, middle panel). These results indicate that NRP1 interacted with and was involved in cMet activation in the sunitinib-adapted cells.

The activation of the downstream effector of NRP1, p130Cas, which is an important NRP1 signaling molecule that activates cell motility (32) was also investigated. The levels of phospho-p130Cas were elevated in the sunitinib-adapted cells compared with the control cells (Fig. 7D, upper panel), while the levels of total p130Cas did not differ between the control and sunitinib-adapted cells (Fig. 7D, middle panel). As previous studies demonstrated that the activation of p130Cas is associated with the induction of the mesenchymal markers Slug and N-cadherin $(33,34)$, the levels of these markers were 


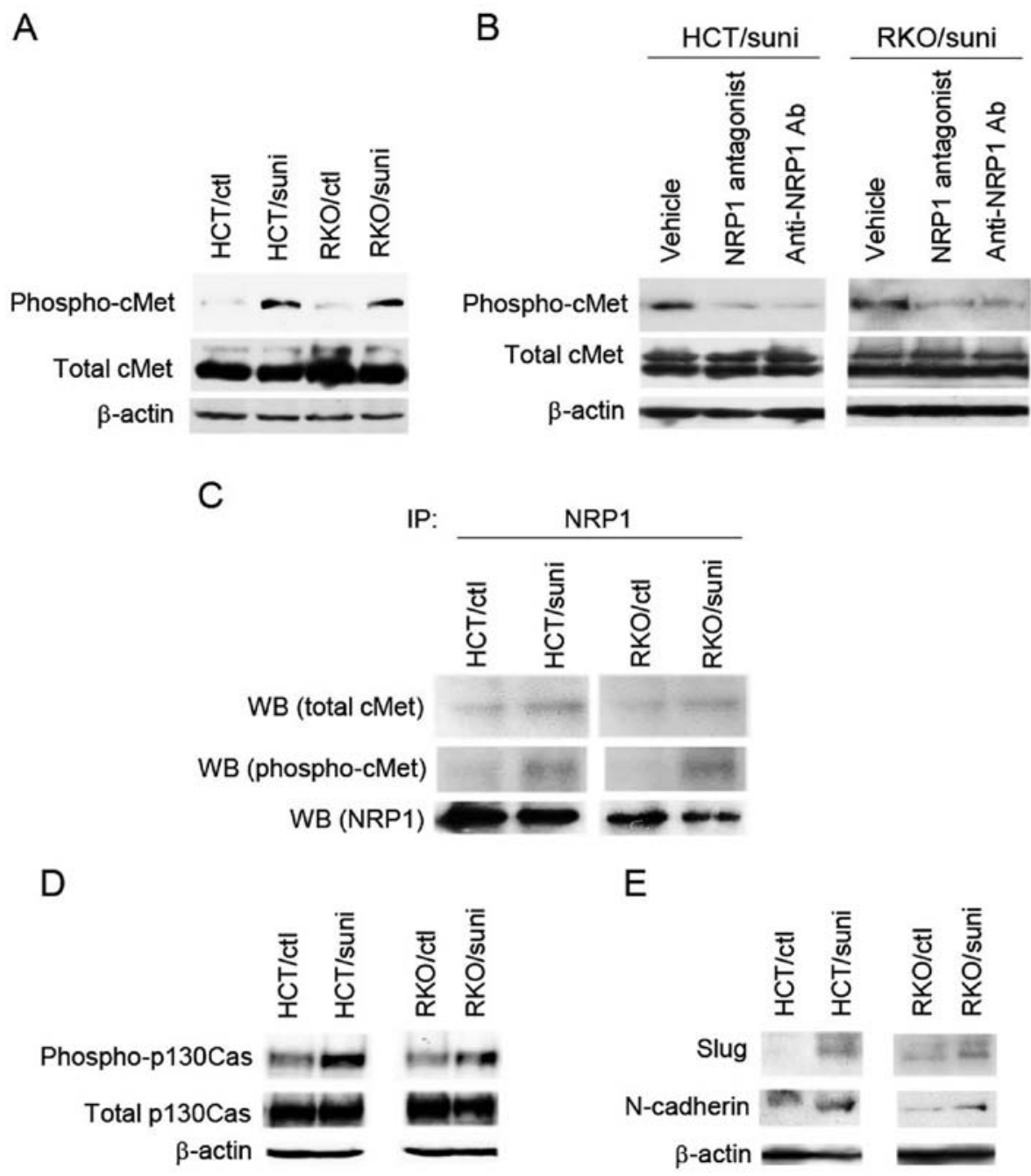

Figure 7. NRP1-dependent cMet activation in the sunitinib-adapted cells. (A) Expression levels of phosphorylated cMet and total cMet were measured by western blot analysis. (B) NRP1-dependent cMet phosphorylation in the sunitinib-adapted cells. The sunitinib-adapted cells were pretreated for $2 \mathrm{~h}$ with vehicle (DMSO), NRP1 antagonist or anti-NRP1 neutralizing antibody, and then analyzed by western blotting using antibodies against phospho-cMet and total cMet, respectively. (C) Interaction of NRP1 with phosphorylated cMet in the sunitinib-adapted cells. NRP1 was immunoprecipitated with anti-NRP1 antibody using cell lysates from the control and the sunitinib-adapted cells. Immunoblotting was performed using antibodies against phospho-cMet, total cMet and NRP1. Western blot analyses were also conducted to determine the expression levels of (D) phosphorylated p130Cas and total p130Cas and (E) Slug and $\mathrm{N}$-cadherin. (A, B, D and E) The levels of $\beta$-actin are shown as a loading control. NRP1, neuropilin-1; cMet, tyrosine-protein kinase Met; DMSO, dimethylsulfoxide; Ab, antibody; HCT/ctl, control HCT116 cells; RKO/ctl, control RKO cells; HCT/suni, sunitinib-adapted HCT116 cells; RKO/suni, sunitinib-adapted RKO cells; IP, immunoprecipitation; WB, western blot.

evaluated in the sunitinib-adapted cells. Consistent with the activation of p130Cas, Slug and N-cadherin expression levels were increased in the sunitinib-adapted cells compared with the control cells (Fig. 7E).

Effect of dual blockade of VEGF-R and cMet on the evasive activation. Based on the aforementioned findings, it was hypothesized that the dual blockade of VEGF-R and cMet would inhibit the NRP1/HGF/cMet adaptive pathway under VEGF-R inhibition conditions. To test this, foretinib was used; this compound inhibits VEGF-R and cMet activities with nanomolar potency (24). Short-term treatment with foretinib for $48 \mathrm{~h}$ did not activate the migration and invasion activities of HCT116 and RKO cells (Fig. 8A and B). By contrast, treatment with sunitinib for $48 \mathrm{~h}$ significantly elevated these activities compared with those of the DMSO-treated control (Fig. 8A and B).

The effect of chronic foretinib exposure for 3 months on the evasive activities of the cells was then evaluated. A foretinib- adapted cell model (HCT/fore and RKO/fore) similar to the sunitinib cell model was established. However, the foretinibadapted cells exhibited a marked activation of migration and invasion, similar to the sunitinib-adapted cells (Fig. 8C and D).

Finally, whether blocking NRP1 was effective in reducing the migration and invasion of the foretinib-adapted cells was examined. Notably, the blockade of NRP1 significantly decreased the migration and invasion activities in these cells compared with the IgG-treated control (Fig. 8E and F), suggesting that the foretinib-adapted cells retained a dependence on NRP1.

\section{Discussion}

In the present study, the direct effects of two different VEGF pathway-targeting drugs, sunitinib and bevacizumab, on the evasive adaptation of colon cancer cells were compared. The results demonstrated that sunitinib activated the migration and 

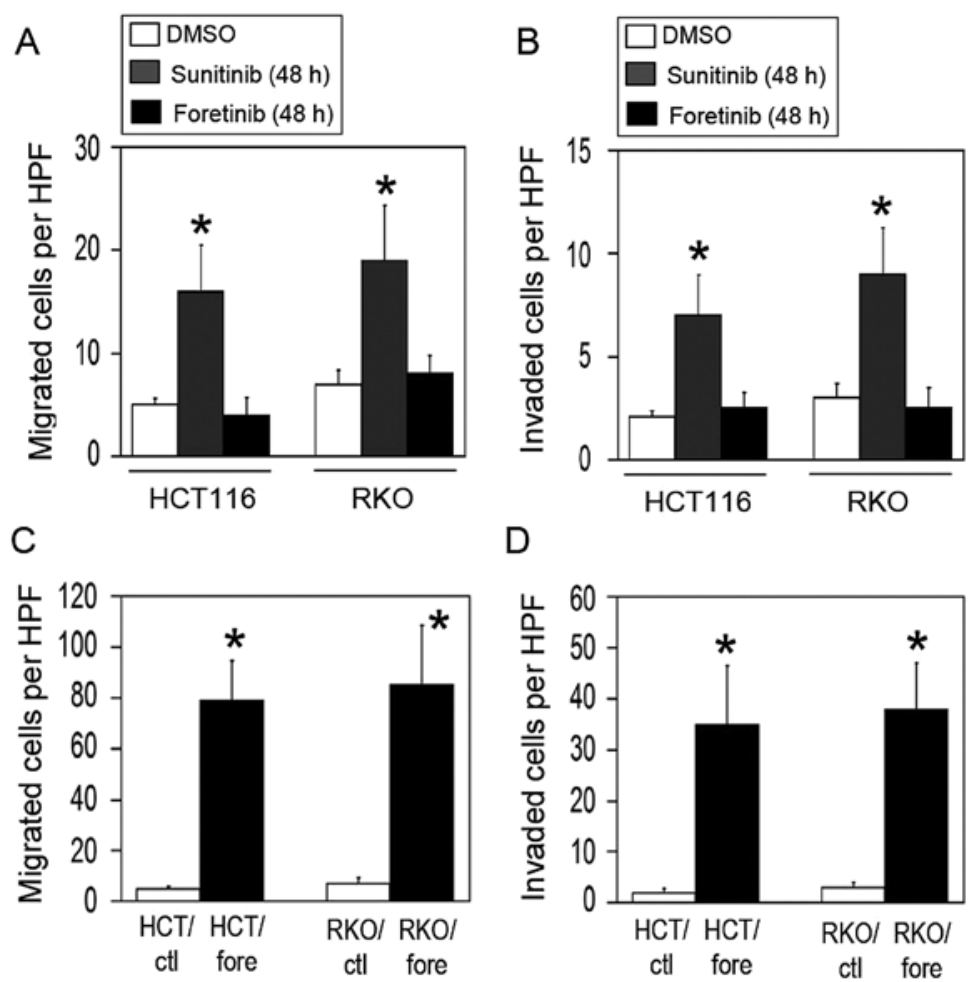

D
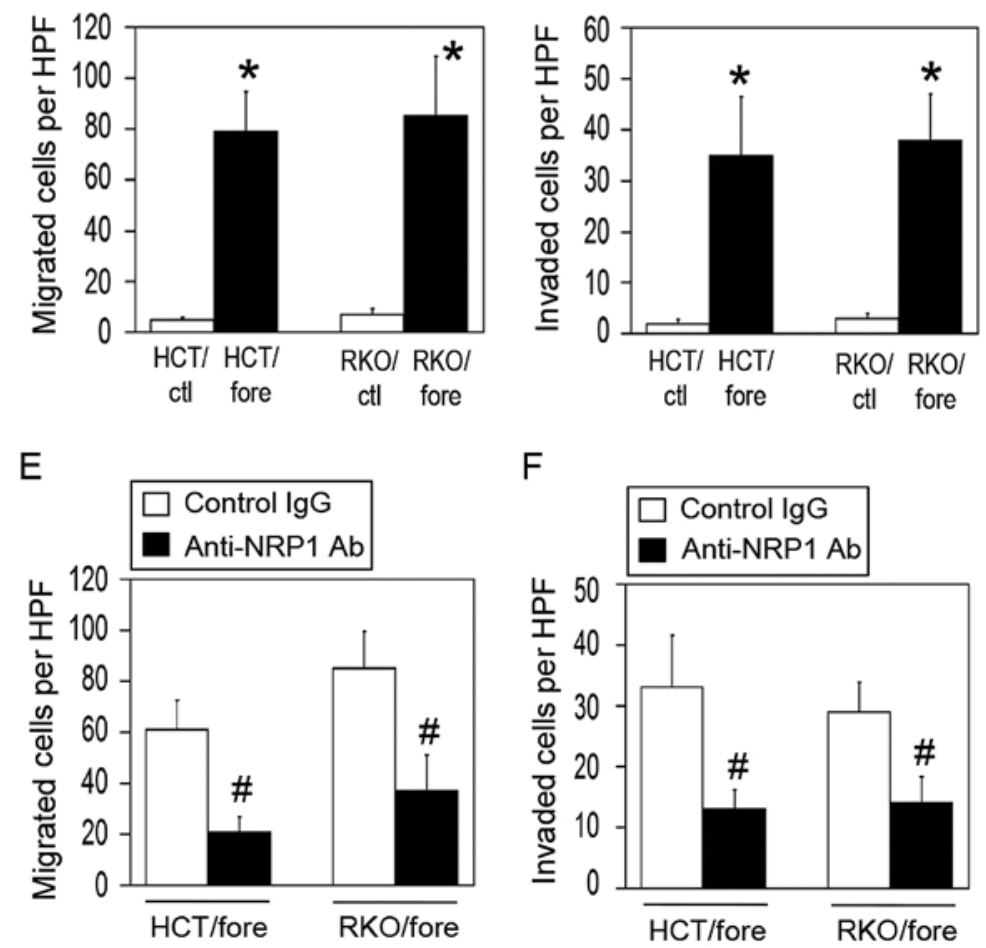

Figure 8. Effect of dual blockade of VEGF-R and cMet on the evasive activation of the colon cancer cells. (A and B) Effect of short-term treatment with sunitinib or foretinib on the migration and invasion activities of colon cancer cells. Following the exposure of parental HCT116 and RKO cells to sunitinib or foretinib for $48 \mathrm{~h}$, the (A) migration and (B) invasion activities of the cells were evaluated ( $\mathrm{n}=4-6$; mean \pm standard deviation). ${ }^{*} \mathrm{P}<0.01 \mathrm{vs}$. the respective DMSO-treated control cells. (C and D) Effect of long-term treatment with foretinib on the migration and invasion activities of colon cancer cells. Parental HCT116 and RKO cells were chronically exposed to foretinib for 3 months, and the (C) migration and (D) invasion activities of the cells were evaluated ( $\mathrm{n}=4-6$; mean \pm standard deviation). HPF, high power field. ${ }^{*} \mathrm{P}<0.01$ vs. the respective DMSO-treated control cells. (E and F) Effect of NRP1 blockade on the evasive activation of the foretinib-adapted cells. The foretinib-adapted cells were pretreated for $24 \mathrm{~h}$ with control (non-immune) IgG or anti-NRP1 neutralizing antibody, and the (E) migration and $(\mathrm{F})$ invasion activities of the cells were evaluated ( $\mathrm{n}=4-6$; mean \pm standard deviation). ${ }^{\#} \mathrm{P}<0.01$ vs. the respective control IgG-treated cells. VEGF-R, vascular endothelial growth factor receptor; cMet, tyrosine-protein kinase Met; NRP1, neuropilin-1; IgG, immunoglobulin G; DMSO, dimethylsulfoxide; HCT/ctl, control HCT116 cells; RKO/ctl, control RKO cells; HCT/fore, foretinib-adapted HCT116 cells; RKO/fore, foretinib-adapted RKO cells; HPF, high power field.

invasion activities of the cells more strongly than did bevacizumab, and by a distinct mechanism. Under the bevacizumab VEGF-A ligand-blocking conditions, cancer cells remained dependent upon the VEGF-R1 and -R3 pathways, as their evasive abilities were significantly decreased by the specific inhibitors of VEGF-R1 and -R3 (Fig. 3F and G). This result is supported by a previous study (21), in which a pan-VEGF-R inhibitor, SU5416, suppresses the motility of bevacizumabadapted cells. By contrast, when all VEGF-Rs were inhibited by sunitinib, cancer cells became dependent on NRP1 and switched from a VEGF-R-dependent pathway to an alternative adaptive one (the NRP1/HGF/cMet pathway) (Figs. 6 and 7).
The present study revealed that NRP1 was required for $\mathrm{cMet}$ activation under conditions where all VEGF-Rs were inhibited by sunitinib. Previous studies have demonstrated that cMet is a critical receptor for the induction of evasive resistance to VEGF/VEGF-R inhibitors in several cancer models (35-37); however, NRP1 did not appear participate in the evasive mechanisms. In a pancreatic neuroendocrine tumor model treated with sunitinib, tumor cell local invasion was accelerated by cMet activation directly induced by hypoxic stress, but not by the direct action of sunitinib on cancer cells (36). In addition, VEGF-R2, but not VEGF-R1, usually interacts with and inactivates cMet in mouse models of glioblastoma multiforme, and 
blocking VEGF-R2 induces the dissociation of the two receptors and thus activates cMet, leading to increased invasive and metastatic activities in vitro and in vivo (35). Notably, NRP1 is not involved in the VEGF-R2/cMet system (35).

NRP1 has been suggested to serve critical roles in cancer progression, since NRP1 overexpression increased the migration and invasion activities of gastric and esophageal squamous cell carcinoma cell lines (38-40). Additionally, NRP1 is preferentially expressed in metastatic cells. For example, NRP1 expression has been detected in MDA-MB-231 metastatic breast cancer and MBA-MB-435 melanoma cells, but not in the MDA-MB-453 non-metastatic cell line and certain nonmetastatic tumors $(41,42)$.

The possible importance of NRP1 in the malignant phenotypes of tumor cells is supported by several clinical studies, including those regarding tumor progression and the poor survival of patients (43-47). In advanced colorectal carcinomas, patients with tumors expressing high levels of NRP1 exhibited a significantly higher incidence of lymph node or liver metastasis than did those with tumors expressing low levels of NRP1 (44). Increased NRP1 expression occurs in gastrointestinal tumors, and this upregulation appears to parallel the invasive behavior of the tumor (43). The survival time of patients with tumors expressing high NRP1 levels is significantly shorter than that of patients with low NRP1 levels (45-47). Therefore, NRP1 is suggested to be a prognostic marker in several cancers and an important target for cancer therapy.

During anti-angiogenic therapy using VEGF/VEGF-R inhibitors, antitumor effects are mainly caused by the reduction of tumor microvessel density and the resulting hypoxic conditions. It is widely accepted that hypoxic stress selects a sub-population of tumor cells and activates several phenotypic changes by which tumor cells are able to survive and progress their malignancy under the hypoxic conditions. However, studies have demonstrated that VEGF/VEGF-R inhibitors directly act on tumor cells and accelerate their malignant phenotypes, independent of hypoxia (18-22). Notably, Han et al (48) demonstrated that simple hypoxic stress is not sufficient to trigger evasive resistance whereas VEGF-R inhibition induces resistance in renal cell carcinoma cells. Thus, malignant phenotypes may be accelerated additively or synergistically by the direct effects of VEGF/VEGF-R inhibitors and hypoxic stress in the tumor microenvironment in vivo.

In the present study, treatment with sunitinib was demonstrated to markedly accelerate the evasive activities of the cells compared with bevacizumab treatment. This is in agreement with previous studies documenting that anti-VEGF antibody therapy does not affect metastasis in mouse tumor models, whereas VEGF-R tyrosine kinase inhibitors, such as sunitinib, promote metastasis $(49,50)$. Additionally, head-to-head comparisons between bevacizumab and sunitinib treatments have been conducted. In a randomized phase III clinical trial in patients with advanced breast cancer, bevacizumab was clinically superior to sunitinib (51). In a randomized phase II trial in patients with advanced renal-cell carcinoma, treatment with bevacizumab produced better efficacy results than were obtained with sunitinib (52).

Based on the findings of the present study and evidence from several reports indicating that activation of the cMet pathway is critical for evasive resistance to VEGF-R-targeting therapy (35-37), it appears possible that a dual inhibitor of VEGF-R and cMet, such as foretinib, may overcome the resistance to VEGF-R inhibitors. Indeed, short-term treatment with foretinib completely suppressed the evasive activation of colon cancer cells in comparison with sunitinib treatment (Fig. 8A and B). However, chronic exposure to foretinib induced evasive activation similar to sunitinib treatment (Fig. 8C and D). Notably, blocking NRP1 suppressed this activation (Fig. 8E and F). These findings suggest that under conditions involving the chronic inhibition of cMet and VEGF-R, cancer cells may switch from the NRP1/cMet pathway to another pathway that remains to be dependent upon NRP1. Therefore, the findings of the present study suggest that targeting NRP1 may represent a promising approach for the treatment of cancer with drugs targeting VEGF-R and cMet. Further studies are required to understand the exact mechanism and molecular interactions of NRP1 under chronic cMet and VEGF-R inhibition conditions.

In summary, it is concluded that VEGF/VEGF-R-targeting drugs directly induced evasive adaptation in colon cancer cells independently of hypoxia. The present study demonstrated that sunitinib markedly activated an evasive phenotype through an alternative NRP1/HGF/cMet axis, while bevacizumab accomplished this through redundant VEGF/VEGF-R1 and VEGF-R3 pathways.

\section{Acknowledgements}

Not applicable.

\section{Funding}

This study was supported in part by grants from Grants-in-Aid for JSPS fellows (grant no. 16J04163 to CT), Grants-in-Aid for Scientific Research (grant no. 15H04931 to STK) from JSPS, and the Princess Takamatsu Cancer Research Fund (grant no. 14-24611 to STK).

\section{Availability of data and materials}

The datasets generated during and/or analyzed during the current study are available from the corresponding author on reasonable request.

\section{Authors' contributions}

CT carried out the cellular, biochemical and molecular biological studies and drafted the manuscript. NY, HN and TU performed cellular studies. AO, KH and TN contributed to experimental design and helped to draft the manuscript. STK designed and directed the study, and helped to draft the manuscript. All authors read and approved the final manuscript.

\section{Ethics approval and consent to participate}

Not applicable.

\section{Consent for publication}

Not applicable. 


\section{Competing interests}

The authors declare that they have no competing interests.

\section{References}

1. Bergers $G$ and Hanahan D: Modes of resistance to anti-angiogenic therapy. Nat Rev Cancer 8: 592-603, 2008

2. Ellis LM and Reardon DA: Is there really a yin and yang to VEGF-targeted therapies? Lancet Oncol 11: 809-811, 2010.

3. Ferrara N: Pathways mediating VEGF-independent tumor angiogenesis. Cytokine Growth Factor Rev 21: 21-26, 2010.

4. Ribatti D: Tumor refractoriness to anti-VEGF therapy. Oncotarget 19: 46668-46677, 2016.

5. Jayson GC, Kerbel R, Ellis LM and Harris AL: Antiangiogenic therapy in oncology: Current status and future directions. Lancet 388: 518-529, 2016.

6. Jayson GC, Hicklin DJ and Ellis LM: Antiangiogenic therapyevolving view based on clinical trial results. Nat Rev Clin Oncol 9: 297-303, 2012.

7. Meadows KL and Hurwitz HI: Anti-VEGF therapies in the clinic. Cold Spring Harb Perspect Med 2: a006577, 2012.

8. Bottsford-Miller JN, Coleman RL and Sood AK: Resistance and escape from antiangiogenesis therapy: Clinical implications and future strategies. J Clin Oncol 30: 4026-4034, 2012.

9. Ebos JM,Lee CR, Cruz-Munoz W, Bjarnason GA, Christensen JG and Kerbel RS: Accelerated metastasis after short-term treatment with a potent inhibitor of tumor angiogenesis. Cancer Cell 15 232-239, 2009

10. Pàez-Ribes M, Allen E, Hudock J, Takeda T, Okuyama $H$, Viñals F, Inoue M, Bergers G, Hanahan D and Casanovas O: Antiangiogenic therapy elicits malignant progression of tumors to increased local invasion and distant metastasis. Cancer Cell 15: 220-231, 2009.

11. Ebos JM and Kerbel RS: Antiangiogenic therapy: Impact on invasion, disease progression, and metastasis. Nat Rev Clin Oncol 8: 210-221, 2011

12. Kieran MW, Kalluri R and Cho YJ: The VEGF pathway in cancer and disease: Responses, resistance, and the path forward. Cold Spring Harb Perspect Med 2: a006593, 2012.

13. Moserle L, Jiménez-Valerio G and Casanovas O: Antiangiogenic therapies: Going beyond their limits. Cancer Discov 4: 31-41, 2014.

14. Piao Y, Liang J, Holmes L, Henry V, Sulman E and de Groot JF Acquired resistance to anti-VEGF therapy in glioblastoma is associated with a mesenchymal transition. Clin Cancer Res 19 4392-4403, 2013.

15. Graeber TG, Osmanian C, Jacks T, Housman DE, Koch CJ, Lowe SW and Giaccia AJ: Hypoxia-mediated selection of cells with diminished apoptotic potential in solid tumours. Nature 379: 88-91, 1996.

16. Semenza GL: Hypoxia-inducible factors: Mediators of cancer progression and targets for cancer therapy. Trends Pharmacol Sci 33: 207-214, 2012

17. Semenza GL: Oxygen sensing, hypoxia-inducible factors, and disease pathophysiology. Annu Rev Pathol 9: 47-71, 2014

18. Goel HL and Mercurio AM: VEGF targets the tumour cell. Nat Rev Cancer 13: 871-882, 2013

19. Simon T, Gagliano T and Giamas G: Direct effects of antiangiogenic therapies on tumor cells: VEGF signaling. Trends Mol Med 23: 282-292, 2017.

20. Videira PA, Piteira AR, Cabral MG, Martins C, Correia M, Severino P, Gouveia H, Carrascal M, Almeida JF, Trindade H, et al: Effects of bevacizumab on autocrine VEGF stimulation in bladder cancer cell lines. Urol Int 86: 95-101, 2011.

21. Fan F, Samuel S, Gaur P, Lu J, Dallas NA, Xia L, Bose D, Ramachandran V and Ellis LM: Chronic exposure of colorectal cancer cells to anti-VEGF $\mathrm{mAb}$ promotes compensatory pathways that mediate tumor cell migration. Br J Cancer 104: 1270-1277, 2011

22. Yamagishi N, Kondo TS, Masuda K, Nishida K, Kuwano Y, Dang DT, Dang LH, Nikawa T and Rokutan K: Chronic inhibition of tumor cell-derived VEGF enhances the malignant phenotype of colorectal cancer cells. BMC Cancer 13: 229, 2013.

23. Huang D, Ding Y, Li Y, Luo WM, Zhang ZF, Snider J, Vandenbeldt K, Qian CN and Teh BT: Sunitinib acts primarily on tumor endothelium rather than tumor cells to inhibit the growth of renal cell carcinoma. Cancer Res 70: 1053-1062, 2010
24. Shah MA, Wainberg ZA, Catenacci DV, Hochster HS, Ford J, Kunz P, Lee FC, Kallender H, Cecchi F, Rabe DC, et al: Phase II study evaluating 2 dosing schedules of oral foretinib (GSK1363089), cMet/VEGFR2 inhibitor, in patients with metastatic gastric cancer. PLoS One 8: e54014, 2013.

25. Pfaffl MW: Relative quantification. In: Real-time PCR. Dorak MT (ed). 1st edition. Taylor \& Francis, London, 2006.

26. Bae DG, Kim TD, Li G, Yoon WH and Chae CB: Anti-flt1 peptide, a vascular endothelial growth factor receptor 1-specific hexapeptide, inhibits tumor growth and metastasis. Clin Cancer Res 11: 2651-2661, 2005.

27. Chang YW, Su CM, Su YH, Ho YS, Lai HH, Chen HA, Kuo ML, Hung WC, Chen YW, Wu CH, et al: Novel peptides suppress VEGFR-3 activity and antagonize VEGFR-3-mediated oncogenic effects. Oncotarget 5: 3823-3835, 2014.

28. Parker MW, Guo HF, Li X, Linkugel AD and Vander Kooi CW: Function of members of the neuropilin family as essential pleiotropic cell surface receptors. Biochemistry 51: 9437-9446, 2012.

29. Prud'homme GJ and Glinka Y: Neuropilins are multifunctional coreceptors involved in tumor initiation, growth, metastasis and immunity. Oncotarget 3: 921-939, 2012.

30. Rizzolio S and Tamagnone L: Multifaceted role of neuropilins in cancer. Curr Med Chem 18: 3563-3575, 2011.

31. Binétruy-Tournaire R, Demangel C, Malavaud B, Vassy R, Rouyre S, Kraemer M, Plouët J, Derbin C, Perret G and Mazié JC: Identification of a peptide blocking vascular endothelial growth factor (VEGF)-mediated angiogenesis. EMBO J 19: 1525-1533, 2000.

32. Evans IM, Yamaji M, Britton G, Pellet-Many C, Lockie C, Zachary IC and Frankel P: Neuropilin-1 signaling through p130Cas tyrosine phosphorylation is essential for growth factordependent migration of glioma and endothelial cells. Mol Cell Biol 31: 1174-1185, 2011 .

33. Bisaro B, Montani M, Konstantinidou G, Marchini C, Pietrella L, Iezzi M, Galiè M, Orso F, Camporeale A, Colombo SM, et al: p130Cas/cyclooxygenase-2 axis in the control of mesenchymal plasticity of breast cancer cells. Breast Cancer Res 14: R137, 2012.

34. Mui KL, Bae YH, Gao L, Liu SL, Xu T, Radice GL, Chen CS and Assoian RK: N-cadherin induction by ECM stiffness and FAK overrides the spreading requirement for proliferation of vascular smooth muscle cells. Cell Rep 10: 1477-1486, 2015.

35. Lu KV, Chang JP, Parachoniak MM, Aghi MK, Meyronet D, Isachenko N, Fouse SD, Philips JJ, Cheresh DA, Park M, et al: VEGF inhibits tumor cell invasion and mesenchymal transition through a MET/VEGFR2 complex. Cancer Cell 22: 21-35, 2012.

36. Sennino B, Ishiguro-Oonuma T, Wei Y, Naylor RM, Williamson CW, Bhagwandin V, Tabruyn SP, You WK, Chapman HA, Christensen JG, et al: Suppression of tumor invasion and metastasis by concurrent inhibition of c-Met and VEGF signaling in pancreatic neuroendocrine tumors. Cancer Discov 2: 270-287, 2012.

37. Mezquita B, Pineda E, Mezquita J, Mezquita P, Pau M, CodonyServat J, Martínez-Balibrea E, Mora C, Maurel J and Mezquita C: LoVo colon cancer cells resistant to oxaliplatin overexpress c-MET and VEGFR-1 and respond to VEGF with dephosphorylation of c-MET. Mol Carcinog 55: 411-419, 2016.

38. Peng Y, Liu YM, Li LC, Wang LL and Wu XL: MicroRNA-338 inhibits growth, invasion and metastasis of gastric cancer by targeting NRP1 expression. PLoS One 9: e94422, 2014.

39. Shi F, Shang L, Pan BQ, Wang XM, Jiang YY, Hao JJ, Zhang Y, Cai Y, Xu X,Zhan QM, et al: Calreticulin promotes migration and invasion of esophageal cancer cells by upregulating neuropilin-1 expression via STAT5A. Clin Cancer Res 20: 6153-6162, 2014

40. Hong TM, Chen YL, Wu YY, Yuan A, Chao YC, Chung YC, Wu MH, Yang SC, Pan SH, Shih JY, et al: Targeting neuropilin 1 as an antitumor strategy in lung cancer. Clin Cancer Res 13: 4759-4768, 2007.

41. Bachelder RE, Crago A, Chung J, Wendt MA, Shaw LM, Robinson G and Mercurio AM: Vascular endothelial growth factor is an autocrine survival factor for neuropilin-expressing breast carcinoma cells. Cancer Res 61: 5736-5740, 2001.

42. Soker S, Takashima S, Miao HQ, Neufeld G and Klagsbrun M: Neuropilin-1 is expressed by endothelial and tumor cells as an isoform-specific receptor for vascular endothelial growth factor. Cell 92: 735-745, 1998.

43. Hansel DE, Wilentz RE, Yeo CJ, Schulick RD, Montgomery E and Maitra A: Expression of neuropilin-1 in high-grade dysplasia, invasive cancer, and metastases of the human gastrointestinal tract. Am J Surg Pathol 28: 347-356, 2004. 
44. Ochiumi T, Kitadai Y, Tanaka S, Akagi M, Yoshihara M and Chayama K: Neuropilin-1 is involved in regulation of apoptosis and migration of human colon cancer. Int J Oncol 29: 105-116, 2006.

45. Ben Q, Zheng J, Fei J, An W, Li P, Li Z and Yuan Y: High neuropilin 1 expression was associated with angiogenesis and poor overall survival in resected pancreatic ductal adenocarcinoma. Pancreas 43: 744-749, 2014.

46. Lee SW, Lee JE, Yoo CY, Ko MS, Park CS and Yang SH: NRP-1 expression is strongly associated with the progression of pituitary adenomas. Oncol Rep 32: 1537-1542, 2014.

47. Zhu H, Cai H, Tang M and Tang J: Neuropilin-1 is overexpressed in osteosarcoma and contributes to tumor progression and poor prognosis. Clin Transl Oncol 16: 732-738, 2014.

48. Han KS, Raven PA, Frees S, Gust K, Fazli L, Ettinger S, Hong SJ, Kollmannsberger C, Gleave ME and So AI: Cellular adaptation to VEGF-targeted antiangiogenic therapy induces evasive resistance by overproduction of alternative endothelial cell growth factors in renal cell carcinoma. Neoplasia 17: 805-816, 2015 .
49. Singh M, Couto SS, Forrest WF, Lima A, Cheng JH, Molina R, Long JE, Hamilton P, McNutt A, Kasman I, et al: Anti-VEGF antibody therapy does not promote metastasis in genetically engineered mouse tumour models. J Pathol 227: 417-430, 2012.

50. Chung AS, Kowanetz M, Wu X, Zhuang G, Ngu H, Finkle D, Komuves L, Peale F and Ferrara N: Differential drug classspecific metastatic effects following treatment with a panel of angiogenesis inhibitors. J Pathol 227: 404-416, 2012.

51. Robert NJ, Saleh MN, Paul D, Generali D, Gressot L, Copur MS, Brufsky AM, Minton SE, Giguere JK, Smith JW II, et al: Sunitinib plus paclitaxel versus bevacizumab plus paclitaxel for first-line treatment of patients with advanced breast cancer: A phase III, randomized, open-label trial. Clin Breast Cancer 11: 82-92, 2011.

52. Négrier S, Gravis G, Pérol D, Chevreau C, Delva R, Bay JO, Blanc E, Ferlay C, Geoffrois L, Rolland F, et al: Temsirolimus and bevacizumab, or sunitinib, or interferon alfa and bevacizumab for patients with advanced renal cell carcinoma (TORAVA): A randomised phase 2 trial. Lancet Oncol 12: 673-680, 2011. 